\title{
Treatment of anterior uveitis
}

\section{Comparison of oral oxyphenbutazone and topical steroids}

\author{
P. J. L. HUNTER
}

Department of Ophthalmology, Norfolk and Norwich Hospital, Norwich

A N D

P. D. FOWLER AND P. WILKINSON*

Medical Department, Geigy Pharmaceuticals, Macclesfield, Cheshire

With the introduction of the corticosteroids in $1948-49$, the treatment of inflammato $\frac{\overrightarrow{0}}{\overrightarrow{0}}$ eye disease was completely revolutionized. Many people have in consequence beeis saved the tragedy of partial sight and the disaster of blindness. So effective have theses drugs been that they are still the first line of attack, and until there is a better treatment, there is no real justification for failure to use them.

The development of pyrazole compounds with their anti-inflammatory, antipyretic, $\frac{\mathscr{D}}{\mathscr{D}}$

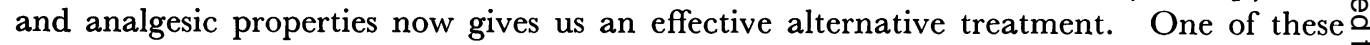
drugs, oxyphenbutazone (Tanderil) which was discovered in 1955 (Burns, Rose, Goodwin, $\overrightarrow{\vec{O}}$ Reichenthal, Horning, and Brodie, 1955) has been shown to possess all these features. Bergaust ( 1962$)$ in a double-blind trial showed that patients with anterior uveitis receiving topical steroids improved significantly when oxyphenbutazone was added to their regimen.

Contraindications to topical steroid therapy do occasionally arise. Their effect in raising the intraocular pressure in both normal and glaucomatous eyes is already well documented. Oxyphenbutazone does not have this effect when used in the form of an 8 ointment (Younessian and Psilas, 1970), and there have been no cases reported after systemic therapy.

Topical steroids are also contraindicated in the treatment of dendritic keratitis and the iritis which so often accompanies it. It has been shown in animal experiments that oxyphenbutazone in the form of ointment locally applied does not enhance virus repli- . cation as do the steroids (Patterson, 1972; Patterson and Jones, I967) and is therefore safe ${ }^{N}$ to use in these conditions.

The object of this trial was to see if there was any significant difference between groups of patients treated with systemic oxyphenbutazone and those treated with topical steroids so that in the event of a contraindication to the latter, oxyphenbutazone could be used in $\stackrel{\oplus}{\oplus}$ its place and achieve a comparable therapeutic result. It is recognized that $\mathrm{I}$ per cent. 0 hydrocortisone is one of the weaker of the commonly used topical steroid applications; $\frac{\partial}{D}$ nevertheless the side-effects of this drug are the same as those of its more potent colleagues. 
Systemic oxyphenbutazone was chosen as no topical preparation of this substance was available at the beginning of the trial.

\section{Material}

The patients studied were selected from those presenting at the Ophthalmic Departments of the Norfolk and Norwich and Great Yarmouth General Hospitals. The criteria for inclusion in the trial were strict. All cases selected were prime cases of non-specific anterior uveitis in which there had been no previous treatment with steroids. A careful history was taken and certain screening tests were carried out at the first attendance: chest $x$-ray, urine, erythrocyte sedimentation rate, blood count, and any other investigation where it was thought the history might be significant; only patients with negative tests were admitted to the trial. This meant that, out of 92 consecutive patients, 62 were unsuitable for inclusion in the trial.

\section{Methods}

Patients admitted to the trial were randomly allocated to one of the following treatment groups: GROUP A Tablets oxyphenbutazone roo mg. four times daily-plus placebo drops 4-hrly. GROUP B Tablets lactose four times daily-plus I per cent. hydrocortisone drops 4-hrly.

In addition, all patients received atropine I per cent.

The tablets of placebo (lactose) were made to match the standard $100 \mathrm{mg}$. Tanderil tablet in size and colouring and packed in matching containers. The hydrocortisone and placebo drops were also matched in appearance and packed in identical bottles.

Each patient was seen at weekly intervals until the end of the trial at Day 28. The same observer assessed each case and the following parameters were recorded on a pre-determined scale:

Corrected visual acuity

Giliary injection

Cells and keratic precipitates

Flare

Exudate

In addition, pain was similarly assessed - this being the only subjective parameter. Provision was made to assess both side-effects and any failure to respond to treatment. In the latter event, the patient was withdrawn from the trial and an alternative treatment instituted.

\section{Results}

Thirty patients entered the trial but, because of default in attendance or treatment failure, only 26 completed it. In some patients both eyes were affected.

The analysis was made on the number of patients who completed the trial.

\section{Examination of results}

This consisted of a modified $\chi^{2}$ method as described by Cochran (1954) performed for individual parameters after an initial comparison of treatment groups to establish their similarity.

Age and sex distribution of treatment groups

26 patients completed the trial. The age and sex distribution is given in Table I (overleaf). The numbers of each sex and the mean ages and age-ranges were similar in the two treatment groups. The male patients were younger than the females, the mean ages being $44 \cdot 3$ and $57 \cdot 0$ years respectively. 
Table I Age and sex of patients

\begin{tabular}{|c|c|c|c|c|c|}
\hline \multirow[b]{2}{*}{ Group } & \multirow{2}{*}{$\begin{array}{l}\text { No. } \\
\text { of } \\
\text { cases }\end{array}$} & \multicolumn{2}{|c|}{ Age (yrs) } & \multicolumn{2}{|l|}{ Sex } \\
\hline & & Range & Mean & Male & Female \\
\hline Oxyphenbutazone & 14 & I $0-8 \mathrm{I}$ & $5^{2.2}$ & 6 & 8 \\
\hline Hydrocortisone & 12 & $22-78$ & $47 \cdot 9$ & 6 & 6 \\
\hline
\end{tabular}

History

The length of time that the patients had experienced symptoms was recorded at the initial assessment; the range is given in Table II.

Table II Length of history, by sex

\begin{tabular}{|c|c|c|c|c|c|c|}
\hline \multirow{3}{*}{$\begin{array}{l}\text { Duration } \\
\text { (days) }\end{array}$} & \multicolumn{6}{|l|}{ Sex } \\
\hline & \multicolumn{2}{|l|}{ Male } & \multicolumn{2}{|l|}{ Female } & \multicolumn{2}{|l|}{ Total } \\
\hline & $H$ & 0 & $H$ & $O$ & $H$ & $O$ \\
\hline $\begin{array}{l}\text { Less than } 7 \\
8-14 \\
\text { More than } 15\end{array}$ & $\begin{array}{l}3 \\
2 \\
I\end{array}$ & $\begin{array}{l}2 \\
2 \\
4\end{array}$ & $\begin{array}{l}\mathbf{I} \\
\mathbf{2} \\
3\end{array}$ & $\begin{array}{l}2 \\
2 \\
2\end{array}$ & $\begin{array}{l}4 \\
4 \\
4\end{array}$ & $\begin{array}{l}4 \\
4 \\
6\end{array}$ \\
\hline $\begin{array}{l}\text { Total } \\
\text { Range }\end{array}$ & $\begin{array}{l}6 \\
2-1800\end{array}$ & $\begin{array}{l}8 \\
3-6 o\end{array}$ & $\begin{array}{l}6 \\
3-6 o\end{array}$ & $\begin{array}{l}6 \\
7-150\end{array}$ & $\begin{array}{l}\text { I } 2 \\
2-1800\end{array}$ & $\begin{array}{l}14 \\
3^{-1} 5^{0}\end{array}$ \\
\hline
\end{tabular}

Side-effects

Only two cases were withdrawn from the trial because of side-effects, one because of drug rash, the other because of persistent diarrhoea. Both were taking oxyphenbutazone.

Effect of treatment on symptoms

PA IN (Fig. I)

This was not a prominent feature in this series of cases. Both groups showed a rapid decrease in pain from Day o to Day 7 and the oxyphenbutazone group was painfree by Day 2 I. The differences between the groups are marginal, and in no period was there a statistically significant difference between the rates of improvement.

GILIARY INJECTION (Fig. 2)

Both groups improved similarly between Day o and Day 7, but the results at Days I 4 and 2 I showed that the patients treated with oxyphenbutazone improved significantly faster than those on hydrocortisone; by Day 28 they were free of ciliary injection.

FLARE (Fig. 3)

Improvement in scores in both groups occurred week by week, although neither group was completely clear by Day 28. The rates of improvement at no time differed significantly between the two treatment groups.

CELLS (Fig. 4)

The two groups showed parallel improvement throughout the trial period. Both had residual scores at Day 28 . There is no significant difference between the rates of improvement. 
KERATIC PREGIPITATES (Figs 5 and 6)

The female patients on hydrocortisone improved significantly faster than those on oxyphenbutazone. In the male patients, the rates of improvement in both treatment groups were similar.

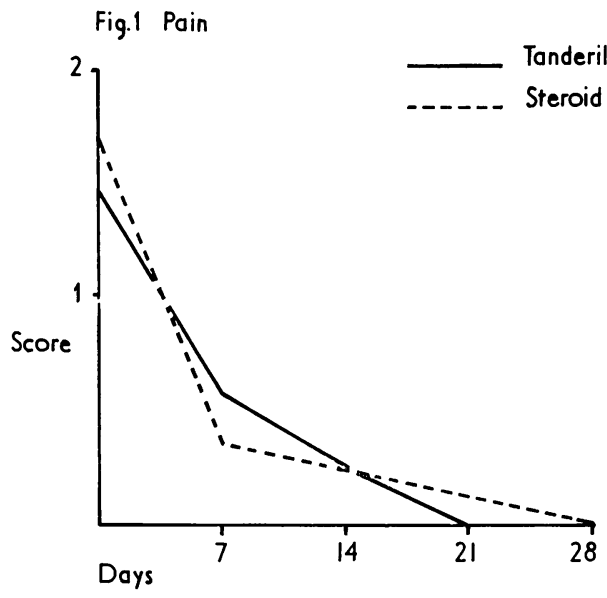

Fig.3 Flare
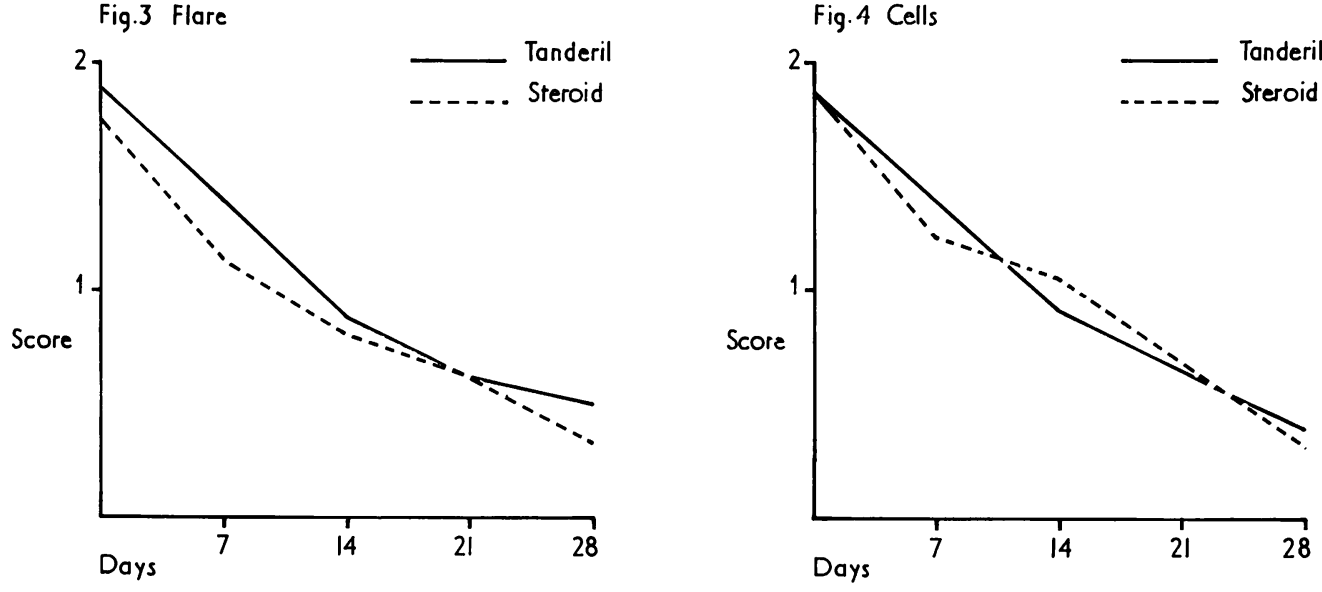

Fig.5 KP Male patients
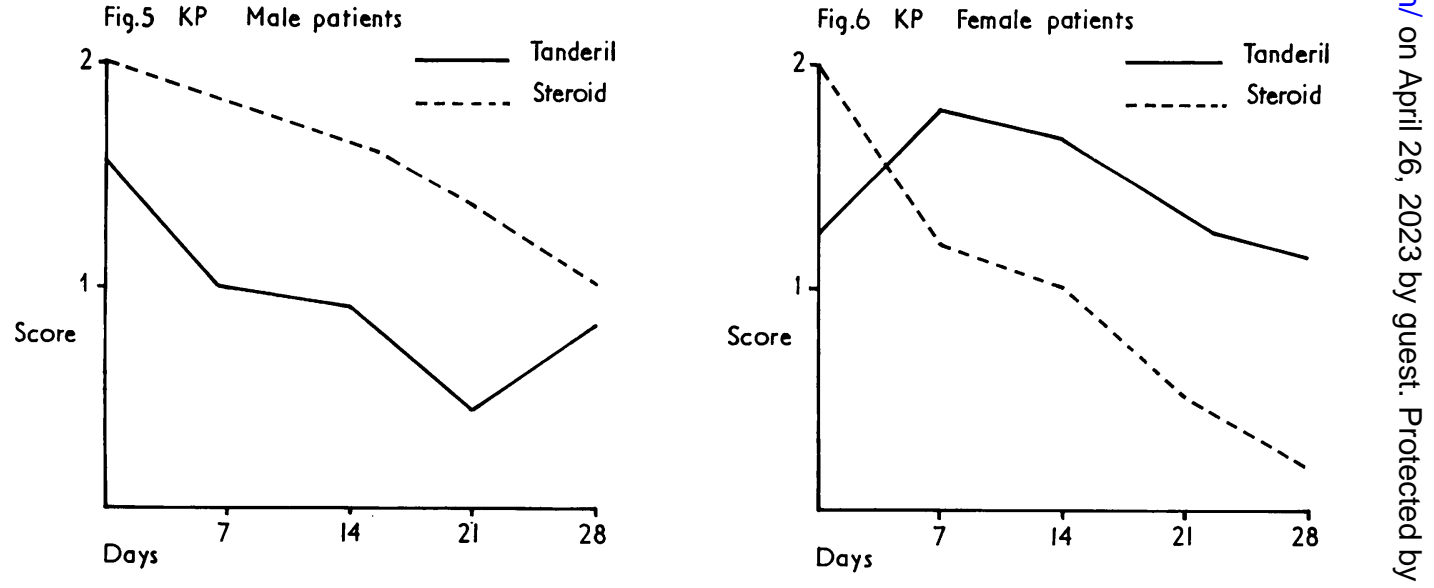
EXUDATES

Improvement was parallel in the two groups and no significant difference in rates of $\frac{0}{.}$ improvement was demonstrated.

\section{Discussion}

Both treatments brought about a substantial improvement as gauged by the chosen parameters. In ciliary injection there is a significant difference in rate of improvement between the two treatments and here oxyphenbutazone brings about more rapid recolution than topical hydrocortisone. Keratic precipitates improved more readily on hydrocortisone in the female patients.

\section{Summary}

A double-blind trial comparing systemic oxyphenbutazone with topical hydrocortisone $\vec{N}$ is described. The results of treatment in 26 cases are analysed. Both treatments are effective. Systemic oxyphenbutazone provides an effective alternative where hydrocortisone is contraindicated.

We wish to thank Mr. J. Seldrup of Ciba-Geigy (UK) Ltd. for help with the analysis of the results, and Geigy Pharmaceuticals for the supply of Tanderil and placebo tablets for the trial.

\section{References}

Bergaust, B. (1962) Acta ophthal. (Kbh.), 40, 379

BURNS, J. J., ROSE, R. K., GOODWIN, S., REIGHENTHAL, J., HORNING, E. C., and BRODIE, B. B. (I955 J. Pharmacol., I13, $48 \mathrm{I}$

COChran, W. G. (1954) Biometrics, 10, 417

patterson, A. (1972) f. int. med. Res., r, 9

- and Jones, B. R. (1967) Trans. ophthal. Soc. U.K., 87, 59

YOUNESSIAN, s., and PSILAS, K. (1970) Ophthalmologica (Basel), 160, 403 